\author{
Alex J Hiller \\ Nottingham Business School, Nottingham Trent University \\ Burton Street \\ Nottingham \\ $U K$ \\ $N G 14 B U$ \\ alex.hiller@ntu.ac.uk \\ $+44(0) 1158484310$
}

Alex Hiller is a Principal Lecturer in Marketing in the Department of Marketing, Retail and Operations at Nottingham Business School, Nottingham Trent University, where he is the Programme Leader for the MSc Marketing. He obtained his MSc in Research Methods from Nottingham Trent University and is currently pursuing a $\mathrm{PhD}$ which investigates the role of ethics in clothing buying decisions. His teaching and research interests include consumer behaviour (particularly ethical consumer behaviour), services marketing and research methods; particularly interpretive, qualitative approaches. Prior to entering academia, Alex worked as a marketing consultant to a range of private and public sector organizations, with a particular focus on marketing research. He has recently been a member of the research team investigating Public Understanding of Sustainable Clothing for the UK Government Department for Environment, Food and Rural Affairs. 


\title{
Challenges in researching consumer ethics: a methodological experiment
}

\begin{abstract}
Purpose - Consumers' ethical shopping habits are of increasing interest, but there has been little discussion and development of the methods used to research them. The purpose of this paper is to reflect on the methodology employed for an empirical study of consumers' ethical concerns in buying clothes.
\end{abstract}

Design/methodology/approach - The study adopts an interpretivist epistemology and interactive approach with the data collection and analysis rooted in grounded theory. More specifically, the study takes an ethnographic approach in the form of existentialphenomenological interviews coupled with accompanied shopping.

Findings - The study reflects on the use of observational methods in researching the role of ethics in consumer clothing choices and finds that they are invaluable in dealing with the challenges of defining ethics, social desirability bias and the problems involved with consumers translating their stated beliefs or intentions into action.

Research limitations/implications - As a pilot study, the research was only conducted with six respondents. Future research should seek to investigate ways to overcome the challenges outlined in this paper; particularly that of social desirability bias. 
Practical implications - There is a need for academics and marketing researchers to adopt innovative observational research methods to investigate ethical consumer behaviour.

Originality/value - Provides a reflection on a unique, emergent approach to researching ethical consumer behaviour. The findings of the research will be of value to anyone researching consumer ethics or buyer behaviour in retail, grounded theorists or those interested in qualitative interactive research techniques.

Keywords Ethical consumption, clothing, participant observation.

Paper type Research paper 


\section{Introduction}

The profile of 'ethical consumerism' has been significantly raised in recent years (Harrison, 2006, Irving, et al., 2005), in turn augmenting studies of ethical consumer behaviour (see for example Memery et al., 2005, Brinkmann, 2004, Bateman et al., 2001, Carrigan and Atalla, 2001). Studies by Valor, 2007, Joergens, 2006, and Shaw et al., 2006 demonstrate that the clothing market is emerging as an area of particular increased consumer concern. In the UK, several top high street fashion retailers have recently announced the introduction of fair trade or organic clothing lines, with a host of specialist (mainly internet-based) ethical clothing companies rising to prominence in the fashion press. However, the methodologies and methods predominantly used in researching consumer ethics often receive little attention despite having profound implications for the results of such research. The vast majority of research in consumer ethics has focused on the use of quantitative scales (for example Vitell and Muncy 1992), and Valor (2007) notes that recent research on ethical buying behaviour has largely adopted similar quantitative methodologies (see for example Shaw et al., 2006). However, Crane (1999: 245) argues that: “...interpretative approaches based on qualitative and/or case study data appear to be under-utilised in the business ethics area despite offering substantial epistemological potential." This is supported by Brinkmann (2004) who calls for the development of qualitative studies of ethical consumption and how the fields of ethics and consumer behaviour can be conceptually linked. Whilst qualitative studies of ethical buying behaviour are emerging (Valor, 2007, Tadajewski and Wagner-Tsukamoto, 2006, Cherrier, 2005, Memery et al., 2005), there have been calls by Gummesson (2007) and 
Lowrey et al. (2005) to use interactive methods in business research and understanding consumers' shopping behaviour.

The purpose of this paper is therefore to reflect on a pilot study of consumers' ethical concerns in making clothing purchase decisions which uses a qualitative, ethnographic approach. The paper is structured as follows: firstly, the background to the problem will be briefly discussed. Whilst it is not the intention of this paper to give a detailed consideration of the context and supporting literature to the specific problem as the aim is to reflect on the research methodology, an understanding of how 'ethics' should be defined is crucial as this has profound implications for the validity of the results . Next, a discussion of and reflection on the research methodology will be given, focusing particularly on the role of an observational research method with data collection and analysis rooted in grounded theory. The problem of social desirability bias will be specifically addressed. Finally, conclusions and recommendations for future research will be made.

\section{Background}

Again, whilst it is not the purpose of this paper to provide a detailed analysis of the conceptual domain underpinning the study, the following context provides the grounding for the research.

Despite evidence to the contrary, Carrigan and Attalla (2001) note that younger consumers are not 'ethically aware' and despite the increased interest in ethical consumption, there is a stark difference between supporting an action and actually engaging in the behaviour oneself. Research by Datamonitor (2005) suggests that whilst 
18-24 year-olds claim to be concerned about ethical issues, they are really only motivated by branding, and Inteletex (2006: online) report that in research from TNS Worldpanel Fashion, $58 \%$ of under $25 \mathrm{~s}$ said they don't care how their clothes are produced. Indeed, Labour Behind the Label (2006: 7) claim that a significant proportion of clothing bought in the UK is: " ... mass-produced, hassle-free, fast, popular, and reliant on exploitation down the supply chain to keep things that way." The overall aim of the research being reflected upon was therefore to gain a greater understanding of the role of ethics in clothing purchase decisions amongst younger consumers. The objectives of the research were to:

- Gain an understanding of consumers' ethical beliefs in the purchase of clothes.

- Discover consumers' levels of awareness of corporate social responsibility in the clothing industry.

- Understand the extent to which consumers' ethical beliefs contribute to value for the customer (VC).

- Explore the extent to which consumers' ethical beliefs influence purchase decisions.

- Explore the extent to which VC is derived from ethically produced clothes.

A study of ethical consumer concerns demands that the study is underpinned by a considered conception of what 'ethical' might actually mean. Donaldson and Dunfee (1994) argue that problems in the field of business ethics stem from the discordant research methods used in its exploration, where it is guided either by empirical ideas (where relationships or behaviour are based on facts which are to be discovered), or by 
normative concepts ('rules' exist which are to be followed). Indeed, as Smith (2001) notes, there is an abundance of literature which focuses on ethics as a normative concept.

However, Bauman (1993: 10) argues that: “...a non-aporetic, non-ambivalent morality, an ethics that is universal and 'objectively founded', is a practical impossibility..." Bauman notes that this is because humans are ambivalent, and this ambivalence cannot be explained by any normative ethical code. Indeed, Valor's (2007) study of information about labour abuses on consumer choice found ambivalence to be the core analytical category. Mackie (1977) also claims that the objective values which have been believed to exist do not. Wiggins (2006) agrees, highlighting that the aim of moral philosophy fails when not grounded in the experiences and lives of individuals, and Creyer and Ross (1997) also note the difficulties in specifying ethical and unethical behaviour as 'ethicality' may be a multi-dimensional concept.

Foucault (in Rabinow, 1984: 343) concurs with the above perspectives, arguing that our problem today is similar to that of the Classical Greeks': “... since most of us no longer believe that ethics is founded in religion, nor do we want a legal system to intervene in our moral, personal, private life." However, this leaves society and individuals with a problem as to what actually constitutes ethics. Whysall (2000: 189) raises concerns that: “...this is a dangerous position, as it implies we cannot expect others to observe standards we think are desirable and necessary, nor can we reasonably criticize or censure the actions of others." Nevertheless, if morality is aporetic, nonuniversalisable, and irrational, it follows that attempts to legislate for ethics or to ascribe to people some sort of ethical code may be largely futile, and concurrently highlights the complexity involved in determining ethical behaviour. However, as previously discussed, 
much of the research into consumer ethics has been guided either by empirical ideas or by normative concepts. To assume that ethical theories must be normative implies ethical absolutism; understanding that this is not necessarily the case is a key underlying foundation of the research methodology; in response a pluralist perspective was adopted in this study as normative standards cannot account for the complex contexts in which ethical decision making may occur. Hinman (2003) notes that in adopting a pluralist approach recognition is given to the existence of differing values which may not be consistent with one another. Indeed, Firat et al. (1995) note in particular that the postmodern consumer may possess multiple (and often contradictory) value systems. Understanding such contrasting points of view through a descriptive account of ethical decision making can therefore assist a deep understanding of consumers' behaviour based on the opinions and actions of those consumers rather than through 'testing' predetermined ethical codes.

\section{Research Methodology}

\subsection{Research Philosophy and Approach}

Due to the concerns outlined in the previous section, the research was based on an interpretive epistemology. As previously noted, studies of ethical consumerism have predominantly adopted positivist methodologies, where ethical decision making processes are defined by objective judgements. However, it was also previously noted that ethics is subjective, contextual, and multi-dimensional. The pluralist ethical position adopted is congruent with a constructionist ontological assumption; it is impossible to treat people as being separate from their social contexts and they cannot be understood without examining the perceptions they have of their own activities (Collis and Hussey, 
2003). The key message of the ethical position, that: "the very search for a single, unifying model of social and cultural life may be inappropriate." (Filmer et al., 1998: 23) means that when examining ethics the ontological assumption must be that human beings are active participants in their lives rather than recipients of larger social forces. As Bryman (2004) notes, adopting the interpretive paradigm naturally leads to qualitative research methods. The lack of comparable research in this area also means that it is, by definition, exploratory. However, the research process in itself was rooted in grounded theory. This is a particularly appropriate approach to take for two key reasons. Firstly, as previously argued the methodological foundation requires that the research does not impose any ethical frames of reference upon the participants. Strauss and Corbin (1998) argue that emergence is the foundation of the grounded theory approach to theory building; such emergence is ideal for developing an understanding of ethical concerns through consumers' own perceptions and experiences. Crane (1999) also argues that such inductive approaches are epistemologically superior to approaches which define ethical terms or norms at the start and which 'force' consumers to respond to them, thus negatively affecting the validity of the results where such concerns may not have even been considered. Secondly, as Valor (2007: 677) notes, grounded theory can assist in providing clarity where: "...past studies have shown contradictions and ambiguities..." which has been the case in understanding consumer ethical concerns as outlined in section 1. Locke (2001) also argues that grounded theory is well suited to complex and practical situations such as the consumer decision making process, but also to the complexity inherent in ethical concerns. 
Finally, also as previously noted, there is a lack of conceptual development in this area. Maital et al. (2008: 7) argue that: "What most differentiates grounded theory from much other research is that it is explicitly emergent... It sets out to find what theory accounts for the research situation as it is.. the aim... is to discover the theory implicit in the data." Grounded theory is therefore a particularly appropriate methodology where there is a lack of data on which to base hypotheses.

\subsection{Research Methods}

Crane (1999) considers that social desirability bias is one of the biggest problems in researching ethics. He notes that survey research in particular may be deficient due to its lack of flexibility in addressing this bias, and Seale (1998) observes that what people say in interviews is not necessarily what they do in practice. To address these salient issues the study adopted an ethnographic approach. Elliott and Jankel-Elliott (2003) argue that such approaches can assist in addressing the issue that people do not always do what they say. Broderick and Lee (2007) and Gummesson (2007) therefore highlight the potential for innovative observational methods to contribute to knowledge in marketing. However, the term 'ethnography' is preferred to 'participant observation' as the study was conducted in the form of existential-phenomenological interviews coupled with accompanied shopping. The interviews preceded and followed the accompanied shopping; a form of phenomenological participant observation. Charmaz (2006: 23) identifies the relationships between a grounded theory approach and this type of ethnography: 
Grounded theory strategies can increase ethnographers' involvement in their research inquiry... In this sense, grounded theory dispels the positivist notion of passive observers who merely absorb their surrounding scenes. Grounded theorists select the scenes they observe and direct their gaze within them.

This process was therefore intended to aid a systematic yet open-ended approach to the research which in turn would aid the process of theoretical development.

\section{The Research Process}

\subsection{Accompanied Shopping}

The aim of this dimension of the research was to assist in uncovering the extent to which consumers' stated beliefs are translated in to action. Accompanied shopping was selected due to its ability to capture shoppers' actual behaviour and allowing respondents to explain their behaviour (Lowrey et al., 2005). The researcher adopted the role of observer-as-participant (Gold, 1958) where observation and interviewing takes place, but little of it as a participant. Whilst a passive role was adopted, the researcher did have interactive involvement in the process. This involvement was considered essential to discover knowledge, attitudes, motives and behaviour. 'Scenes' were determined by the respondents' preferred retailers, and whilst an unstructured approach was taken to the accompanied shopping to allow for specific sets of circumstances, a guiding structure was determined to find out relevant information (without imposing ethical judgments). This was based around the buyer decision process model (Mowen, 1988), with data collection being in the form of informal discussion. 


\subsection{Interviews}

Lowrey et al. (2005) recommend the use of depth interviews with accompanied shopping in order to acquire valid and reliable perspectives on shopping behaviour. Likewise, Elliott and Jankel-Elliott (2003) note that participant observation is usually used with other methods of data collection, and typical examples may include 'life-history' interviews. Cherrier (2005: 127) recommends existential-phenomenological interviewing, which she defines as: “... a way to attain a description of everyday experience as it is lived and described..." This approach is congruent with the ontological position described in sections 2 and 3.1, and Cherrier argues that this existentialist approach is the most appropriate way to investigate ethical consumption due to the inherent link with freedom of choice and the implications of that choice for the individual and society as a whole. Seale (1998) also observes that 'depth', 'unstructured' or 'life history' interviews are more likely to gain more authentic accounts than others, again helping to address concerns over social desirability bias.

A key consideration was the focus and sequence of the questioning relating to ethical consumption; unlike Cherrier's (2005) research, this study seeks to gain insight into the experiences of people who do not necessarily primarily identify themselves as being 'ethical consumers'. There is a potential danger in introducing specific questions about ethical consumption because (as Crane, 1999, suggests) it is unlikely that a person would admit to not being ethical, and it is also important that respondents do not feel as if they are being 'judged'. In addition, Clavin and Lewis (2005) suggest that consumers can find evidencing their ethical choices difficult. The interviews were therefore conducted 
prior to and following from the accompanied shopping. Pre-observation interviews aimed to understand the experiences and attitudes of consumers related to their purchase of clothes without explicitly mentioning ethical issues to prevent the 'actions' of the participant being influenced by a desire to appear to 'be ethical' (a discussion of research ethics is given in section 4.5). It was revealed to the respondent at the post-observation interview that a particular interest was on ethical concerns, and this allowed them to reflect on some of the issues that may have occurred during the observation. Primarily, this stage allowed a discussion of the respondent's awareness and understanding of specific ethical issues, and their engagement in any ethical activity that may not have been manifest during the observation.

\subsection{Sample}

The focus of this study was on those consumers identified by Cowe and Williams (2000) as the 'brand generation'; younger consumers (particularly females) at whom most high street fashion is aimed (Mintel, 2008). The most appropriate and comprehensive profiling of these consumers is given by Experian's (2003) Mosaic consumer type of 'Urban Intelligence'; people who are likely to live in inner-city areas of large provincial cities, particularly those with popular universities. They are likely be aged between 18 and 30 , well educated, and with no children. Many will rent houses and they will be mixed in terms of income. They are likely to be enthusiastic but knowledgeable consumers and media-literate. The respondents were drawn from inner-city areas of provincial university cities in the East Midlands.

Six individuals constituted the sample for this pilot study, so theoretical saturation or selective sampling could not be achieved. Open sampling within the broad 'urban 
intelligence profile' was adopted initially, and underneath the main theoretical sampling

frame a combination of convenience sampling and snowball sampling was employed.

This was achieved by making contacts through personal networks ('friends of friends') to identify potential participants, although respondents directly known by the researcher were not included. As the project was unfunded, no incentives were offered to take part, although participants who were willing to assist in the research were identified. Bryman (2004) and Strauss and Corbin (1998) note that convenience sampling is not necessarily negative where it presents an opportunity not to be missed, but especially where a research instrument is being piloted before an investigation. Whilst more participants may have been desirable to aid theory generation, the primary purpose was to reflect on the methodology and methods employed. The final profile information of the participants is contained in figure 1 .

\begin{tabular}{|c|c|c|}
\hline $\begin{array}{l}\text { Respondent's } \\
\text { pseudonym }\end{array}$ & Profile characteristics & $\begin{array}{l}\text { Consumer type within } \\
\text { 'urban intelligence' } \\
\text { profile }\end{array}$ \\
\hline Karen & $\begin{array}{l}\text { Karen is } 30 \text { years old and was a Volunteer Coordinator for a } \\
\text { large charity prior to recently being made redundant. She is } \\
\text { currently seeking alternative employment in the same field. } \\
\text { Karen lives within half a mile of the city centre and has an } \\
\text { HND in Illustration as well as vocational qualifications in } \\
\text { Multimedia Design and Graphics. She is single with no } \\
\text { children. }\end{array}$ & Caring professional \\
\hline Lisa & $\begin{array}{l}\text { Lisa is } 26 \text { years old and an Income Officer for a housing } \\
\text { association who started working immediately after finishing } \\
\text { 'A' levels. She owns her own home in the city centre with her } \\
\text { partner. }\end{array}$ & Dinky \\
\hline Joanne & $\begin{array}{l}\text { Joanne is } 23 \text { years old. She is studying part-time for a degree } \\
\text { in physics from the Open University and works part-time at a } \\
\text { University as a secretary to a research group. She is single, } \\
\text { lives at home with her parents in the city, and plans to go } \\
\text { travelling after finishing her degree. }\end{array}$ & University \\
\hline Jane & $\begin{array}{l}\text { Jane is a final year student on a business degree. She is } 21 \\
\text { years old and lives in rented accommodation close to the city } \\
\text { centre. As part of her degree she has just completed a year's } \\
\text { industrial placement working in various roles in a large retail } \\
\text { outlet for a national retailer. She is single with no children. }\end{array}$ & University challenge \\
\hline Claire & $\begin{array}{l}\text { Claire is } 28 \text { and a Marketing Manager for a firm of } \\
\text { Management Consultants in a nearby city. Since graduating } \\
\text { she has worked in the consultancy profession and as a }\end{array}$ & $\begin{array}{l}\text { Whilst living in the } \\
\text { Capital Claire may } \\
\text { have most closely }\end{array}$ \\
\hline
\end{tabular}




\begin{tabular}{|l|l|l|}
\hline & $\begin{array}{l}\text { Marketing Manager for a large property consultancy in the } \\
\text { Capital. She is single and now lives within 1 mile of a nearby } \\
\text { city centre in shared rented accommodation. }\end{array}$ & $\begin{array}{l}\text { resembled the 'city } \\
\text { adventurer' profile, but } \\
\text { she also shares } \\
\text { characteristics with } \\
\text { 'town gown } \\
\text { transition'. }\end{array}$ \\
\hline Katie & $\begin{array}{l}\text { Katie is a final year student on a business degree. She is 21 } \\
\text { years old and lives in rented accommodation close to }\end{array}$ & $\begin{array}{l}\text { University challenge } \\
\text { Nottingham city centre. As part of her degree she has just } \\
\text { completed a year's industrial placement working in } \\
\text { communications for a multinational fast food company. She is } \\
\text { single with no children. }\end{array}$ \\
\hline
\end{tabular}

Figure 1: Profile information of participants

\subsection{Data Collection and Analysis}

Data collection occurred during both weekends and weekdays in a large city centre in the East Midlands of England. Interviews took place in cafes immediately prior to and after the participant observation. Interviews were recorded using a high quality digital voice recorder and, despite the noisy locations, all conversations were recorded extremely clearly. Transcription was completed immediately after data collection.

A two-stage coding process was adopted in line with Charmaz's (2006) recommendations: Open coding (developing broad categories until category saturation occurs) and selective coding (identifying the most common and revealing categories around which others appear to be linked). Locke (2001) notes that Glaser considered these two stages sufficient. Open coding began immediately after the initial interviews (through which central ideas and themes in the data were identified). This was done by fully transcribing the discussions and coding the data in the margins by incident Respondents were also coded by their Mosaic profile, although there was insufficient variation across profiles except 'university challenge' (UC) to undertake any meaningful analysis. Initial coding was completed quickly and spontaneously for each segment of data, using actions in the data rather than pre-determined categories. This enabled the 
comparison of incidents without making the analysis too descriptive. From here selective coding could take place (the process of integrating and refining these categories to develop theory). Strauss and Corbin (1998) note that coding for process can give a different analytic focus. There are two subtle processes inherent in this piece of work; firstly, the process of the research itself, and within this the process of consumer behaviour from need recognition through to post-purchase evaluation as displayed in figure 2:

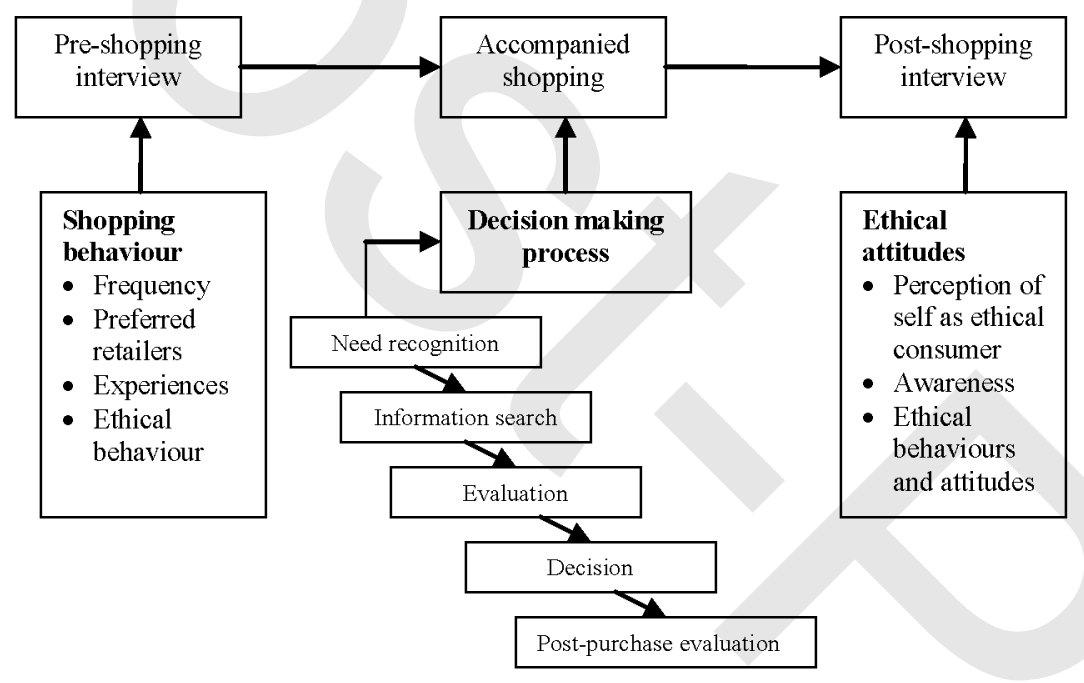

Figure 2: The research process

Selective coding was therefore completed in the processes (under the headings of 'shopping habits and experiences' (SHE), 'purchase behaviour' (PB) and 'ethical attitudes' (EA) which framed the data collection by reading within and across the transcripts. Figure 3 displays the most frequently occurring codes developed under each of these headings, with an indication of suggested relationships and their directions. 


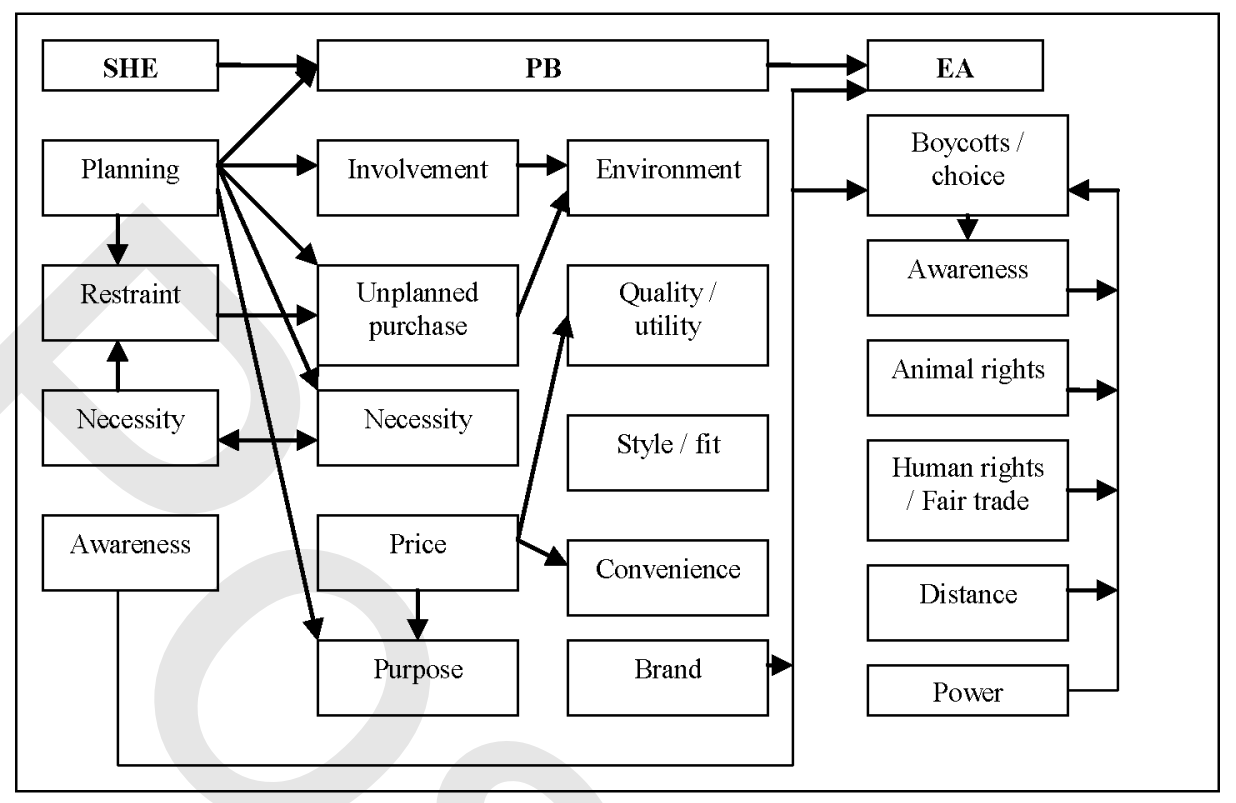

Figure 3: Selective codes

It should be noted that Silverman (2001: 71) argues that if: "Used unintelligently, it [grounded theory] can degenerate into a fairly empty building of categories or into a smokescreen used to legitimize purely empiricist research." To counter these concerns a constructivist approach was taken (Charmaz, 2006), establishing how meanings and actions were constructed in specific situations. In analysis, therefore, codes were compared with the previous incidents coded in the same category, and narrative assembled for each category to 'pull together' disparate experiences. Analysis was then conducted by the constant comparative method during which relationships could be explored. Memos were completed on categories as they began to emerge. Adopting this systematic approach to data analysis ensured reliability (due to constant comparison) and validity (due to ongoing subsequent rounds of data collection) (Strauss and Corbin, 1998). Memos were not intended to contain detailed analysis (this was conducted at a later stage). Rather, ideas, connections and narratives based upon the selective codes 
were produced in order to organise the data into themes which formed the basis of further analysis. Eight memos were constructed in total (see figure 4 for an example):

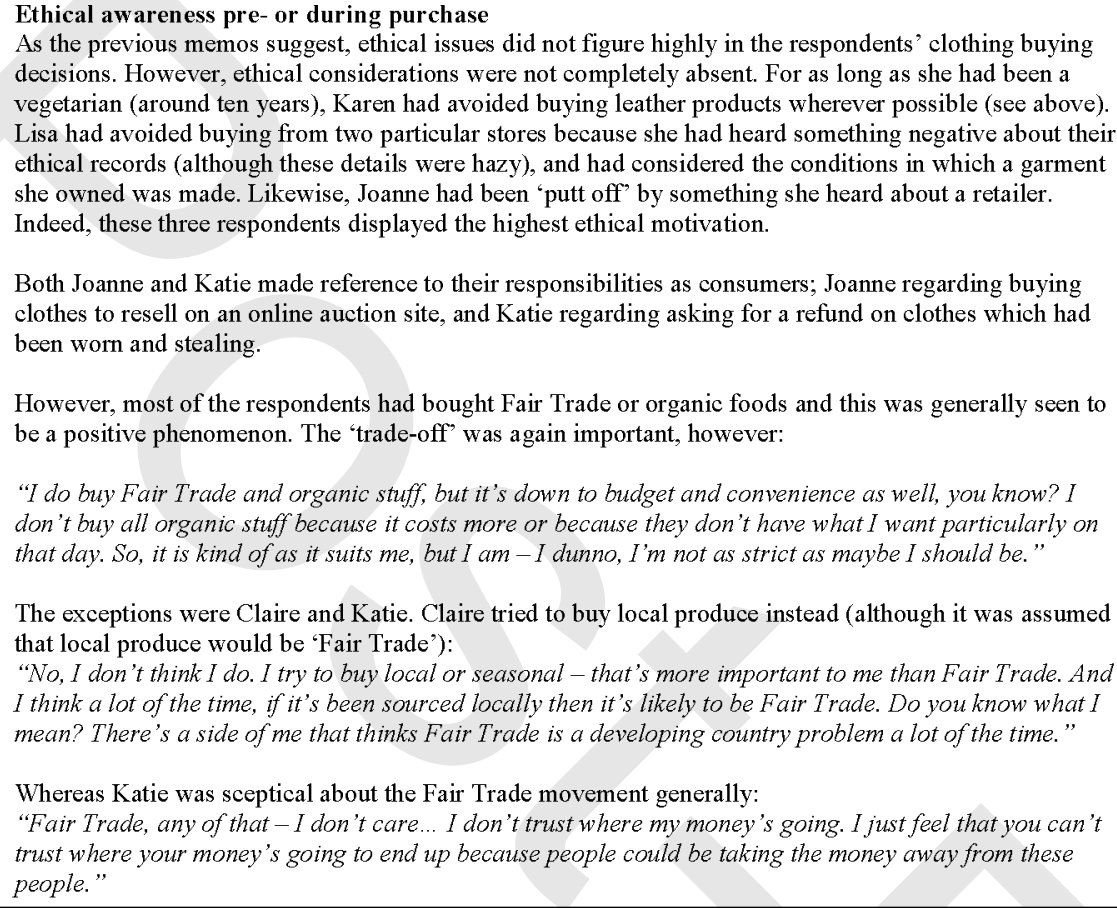

Figure 4: Example of a memo

Once the analysis had been undertaken, comparisons were made with previous studies to explore aspects of similarity and difference. Overall the research found that purchase planning was a central issue in consumer behaviour in this context, but that low levels of consumer awareness of ethical issues rarely meant that these issues featured in such planning or actual buyer behaviour. Rather, as Carrigan and Attalla (2001) suggest the price and purpose of garments and issues of quality, style, fit and fashion were the most important issues, alongside the importance of convenience and the store environment. Specific ethical issues encountered related to animal rights or fair trade, but these rarely affected purchase decisions. However, making 'ethical' purchases had the ability to 
positively influence post-purchase emotions. As suggested by Bauman (1993) and Valor (2007) the differences in consumer opinion expressed do suggest that ambivalence is a key factor.

\subsection{Ethical Considerations}

Respondents were given the details of the research at the point of 'recruitment', and were required to sign a declaration of informed consent. However, due to the issue of social desirability bias, participants were told that the aim of the study was to gain insight into attitudes, beliefs and behaviour when purchasing clothes, but they were not told that the specific objectives related to ethical attitudes and behaviour until the start of the postshopping interview. Diener and Crandall (1978) argue that where no risks are posed to candidates the absolute necessity of informed consent is questionable and it may be methodologically undesirable. It is considered that methodological considerations outweigh the strict principle of informed consent. The British Sociological Association [no date] note that in such circumstances informed consent should be sought post-hoc and that anonymity must be assured.

It was unlikely that any situations would arise where participants would be subject to any potential physical harm, although power relations may be a factor. Mishler (1991) argues that meanings in interviews are contextually grounded, and that the intervieweeinterviewer relationship is characterised by a significant, asymmetrical power relationship. He proposes that respondents may be empowered; encouraged to open up through shifting the relationship to 'informant and reporter' (a technique which is often found in ethnographic research). This technique was employed by the use of informal and discursive questioning. Anonymity was assured by structuring questions in a way that 
would not extrapolate personal information which may identify an individual.

Respondents were assigned pseudonyms prior to transcription and analysis.

\section{Methodological Reflection}

As previously stated, it is not the purpose of this paper to discuss the results of the research in detail. Rather, the purpose is to reflect on the methodology and methods employed.

\subsection{Methodology and Method}

The ontological and epistemological standpoints were appropriate; the individuals involved did display buying behaviour and attitudes based on their own perceptions and social contexts. However, in examining buying behaviour based on ethical considerations there may be aspects of explanation that a phenomenological epistemology overlooks. The very nature of this research is attempting to understand both attitudes and behaviour and the relationships that exist between them. The ethnographic element to the research attempted to address the latter without resorting to the objective, non-contextually grounded quantitative methods which aroused the concerns of Crane (1999) and Brinkmann (2004). However, as the data in section 4.4 suggests, the ethnographic element of the research uncovered a great deal of data which was not directly relevant to the research questions, and the post-shopping interviews offered limited time to discuss issues of ethics. There are two possible solutions: firstly, to remove the accompanied shopping, conducting instead one depth interview which would discuss buying habits and then introduce an ethical element. Alongside this introduce a wider quantitative study via a triangulation approach, where the results of one research strategy are cross-checked 
with the 'opposing' strategy (Gilbert, 2001). Alternatively, to 'intervene' in the shopping phase by introducing predetermined retailers as case studies, either where 'ethical' clothing will be found or who communicate the importance of ethical values through their brands (Edvardsson et al., 2006), or to undertake 'pantry audits' as a basis for depth interviews. No 'ethical' clothing lines or stores were encountered during the accompanied shopping; it was therefore difficult to assess customer reactions to these products. The latter may be the most appropriate strategy in order to retain the epistemological underpinning of the research.

\subsection{The Sample \& Access}

Use of the consumer profile was to try and capture the many dichotomies that exist within studies of young people's ethical consumption. It is argued that they possess immense spending power and are those who are the most likely to support businesses which pursue ethical agendas. The assumption is that if this group of consumers does not purchase ethically, other less educated and affluent consumers would certainly not. Strauss and Corbin (1998) argue that the first consideration for theoretical sampling is that a group to study must be chosen which is directed by the research question, and during open sampling this is likely to be directed by convenience. During discriminate sampling, however, the researcher chooses those subjects which will maximise opportunities for comparative analysis. The respondents in this study were chosen purely on the basis of convenience within the sampling frame, as is often necessary for ethnographers (Bryman, 2004, Walsh, 1998). However, this will become more problematic for future research when theoretical sampling needs to be developed, so issues of access will need careful consideration. This is particularly true when one 
considers that the time required to be spent with participants is reasonably significant. Consideration should be given to incentivising participation and advertising for subjects via appropriate media wherever required. A mix of demographic characteristics should be sought during future research in order to develop theoretical sampling.

\subsection{Data Analysis}

The two-stage coding process was intended to reinforce the inductive approach, whilst using narrative in the memos to be consistent with the interpretive epistemology. Whilst this was useful for identifying the broad themes that emerged from the interviews, the extent to which these themes may have emerged without the coding process is questionable. However, Silverman (2001) warns against reporting which is merely a description of the researchers' impressions which may have occurred if no analytical framework had been applied. Elliott (2005) argues that there are two broad frameworks which can guide qualitative narrative analysis; holistic analysis which seeks to preserve a narrative in its entirety, and categorical analysis in which short sections of the text are extracted and placed into categories. The use of narratives in memos and the comparative analysis both within and between cases sought to maintain the integrity of the context of the narrative. However it could be argued that a focus on categorisation 'lost' some of that contextualisation; that the focus on content and cross-case analysis was at the expense of the form or social function of each narrative. However, Miles and Huberman (1994) argue that cross-case analysis deepens understanding and explanation, and enhances generalisability. Elliott (2005) also asserts that to adopt only an holistic or categorical framework would be something of an oversimplification; researchers should examine both the context and the content. To achieve both, Miles and Huberman (1994) 
therefore recommend interactive synthesis - a phenomenological approach in which synopses of individual cases are written, followed by a cross-case narrative with themes. A compact description of the characteristics common in the transcriptions is then conducted, before finally situating the analysis in a more conceptual frame. This involves analysing several transcriptions, extracting a general psychological profile, and then using that profile on another set of transcriptions, constantly cross-checking. Inductive coding can still be used in this process, but a more holistic approach to the data could be adopted than was the case in this research.

\subsection{Reliability, Validity and Other Practical Issues}

Foucault (2002) argues that research does not 'find' things but 'creates' them through the perspective of the researcher. It therefore follows that there can be no knowledge which is free from values. Qualitative research in particular has been questioned regarding its reliability (Charmaz, 2006). However, the constructivist approach taken to grounded theory in this study recognises that analytic directions emerge from how the researcher interacts with and interprets categories and comparisons, rather than from external sources. Participant observation studies are high in ecological validity (Saunders et al., 2007), but as Lowrey et al., 2005 note, observer bias is unavoidable; the role of the researcher is to recognise this and attempt to control such bias. It could be argued that the largest threat to validity comes from objectively defined quantitative studies which seek to achieve generalisability and replicability. Steps were taken to address issues of reliability and validity through the analytical processes. However, there were also some practical issues in data collection which may affect the reliability and validity of the 
study. Henn et al. (2006) consider that reactivity is a key issue in conducting qualitative research, that is, the behaviour or responses of respondents changes because they know they are being researched. This was addressed by adopting an informal style to the questioning and developing a rapport with participants in the early stages. The existential-phenomenological approach to interviewing also attempted to remove interviewer bias by avoiding objective judgements. However, as Cherrier (2005) notes, a key feature of these interviews is that the researcher offers opinion and joins in the discussion. Whilst this assists in addressing reactivity, a subjective element is naturally introduced. Indeed, exchanges often invariably shifted from informant and reporter. Developing the interview guides may help to avoid this in future research. Indeed, it is questionable whether interviews were truly 'existential-phenomenological'; respondents often did not offer the rich narrative which might be expected to flow from this style of interview. It is recommended in future research that interviewing adopts the format of a more 'traditional' semi-structured interview.

\subsection{Research Ethics}

The key ethical consideration was the extent to which respondents should be given informed consent. The approach taken revealed a broad gap between beliefs and action; this may not have been the case if ethics had been revealed to be the focus at the start. However, Seale (1998: 207) notes that under the feminist perspective: "The implied goal of an objective social science is seen as a sham, brought about to hoodwink respondents into exploitative social relationships." He notes that it could be argued that social researchers should be completely upfront about their objectives, offering personal opinions and stories to the respondent. The problem with this approach is that subjects 
may feel pressure to conform to the interviewers' beliefs. Developing ways of demonstrating an awareness of issues of trust and the influence of any demographic or other factors is therefore recommended. These considerations also go some way to addressing the issue of power relations in the study. Elliott (2005) notes that the unstructured method of interviewing empowers respondents. However, in line with Mishler's (1991) assertion, interview guides and the style of interviewing should be developed to enforce the roles of 'informant and reporter'.

\section{Conclusions}

This paper has attempted to demonstrate that there are three salient issues which must be considered when researching ethical consumer behaviour. Firstly to assume that an objective and universal ethics exists is misguided. Consumer decision making processes and ethical choices are complex, and consumers are ambivalent and possess multiple value systems. The emergence of theory offered by grounded theory offers significant epistemological benefits to researchers here. Secondly, the problem of social desirability bias must be addressed. Surveys are likely to be particularly inefficient in handling this bias, but interviews may also have their problems. Observational methods can be invaluable in discovering actual behaviour, in retail contexts. Finally, regardless of a consumer's intentions or beliefs, there may be various barriers to these intentions being translated into action, and observational methods coupled with interviewing techniques can help to uncover these differences.

As Lee and Broderick (2007) observe, ethnographic approaches are uncommon amongst scholarly marketing researchers. However, the ethnographic, observational 
aspect of the research was effective in dealing with a number of these challenges and these types of approaches should be considered by other academic or commercial researchers of consumer ethics, or in the retail domain more generally where the difference between stated beliefs and action may be a threat to the validity of the research. Nevertheless, there are two key issues which should be addressed for future research:

Firstly, the study generated a wealth of data of little direct relevance to the research objectives, and whilst this was telling in itself, the process may have been improved by introducing ethical elements earlier in the research process. It was argued that the pluralist ethical position adopted should avoid placing such constraints on respondents; however, this position does not have to change within a more focused study examining specific aspects of ethics. It should be noted, however, that Whysall (2000) warns that care should be taken with 'single issue ethics' as frequently a single area of ethical complexity will bring together a number of areas of ethical concern. Interview guides may therefore begin with open-ended questions about ethical behaviour and attitudes, and narrow the focus pertaining to specific issues raised. The interpretation of key words such as 'ethics' can then be derived from the data itself and the comparative analysis. Therefore, whilst the 'structure' imposed by the interview is not purely inductive, salient problems or theoretical concepts will be determined by the respondent and emerge through theoretical sampling.

Secondly, Silverman (2001) draws attention to the ongoing debate regarding bias in interview data and cites the work of Whyte, who claims that in examining subjective material, the interviewer recognises the ambivalence of the human condition. The 
research methods themselves and the data analysis were conducted in a way so as to minimise interviewer bias. It is recommended, however, that analysis adopts an approach similar to Miles and Huberman's (1994) interactive synthesis in order to boost reliability by allowing a cross-case analysis whilst retaining an interpretive and constructivist approach.

Lee and Broderick (2007) highlight their optimism about the potential contribution of observational research in marketing; this paper has demonstrated that there is certainly a role for such methods in researching ethical consumer behaviour and to the retail sphere more generally. Future research should investigate build upon these findings to investigate how research into ethical consumer behaviour can address the problem of social desirability bias and actual consumer behaviour whilst retaining the conceptual integrity of a subjective and non-prescriptive ethics. 


\section{References}

Bateman, C.R., Fraedrich, J.P., and Iyer, R. (2001), "Framing effects within the ethical decision making process of consumers", Journal of Business Ethics, Vol. 36, pp. 119140.

Bauman, Z. (1993) Postmodern Ethics. Oxford: Blackwell.

Brinkmann, J. (2004), "Looking at Consumer Behaviour in a Moral Perspective", Journal of Business Ethics, Vol. 51, pp. 129-141.

British Sociological Association [no date]. Statement of Ethical Practice [online].

Available at: $<$ http://www.socresonline.org.uk/info/ethguide.html $>$ [Accessed 12 December 2007].

Bryman, A. (2004) Social Research Methods ( ${ }^{\text {nd }}$ Ed.). Oxford: Oxford University Press. Carrigan, M., and Atalla, A. (2001), "The myth of the ethical consumer; do ethics matter in purchase behaviour?", Journal of Consumer Marketing, Vol 18 No. 7, pp. 560-577.

Charmaz, K.C. (2006) Grounded Theory: Methods for the 21st Century. London: Sage Publications

Cherrier, H. (2005), "Using Existential-Phenomenological Interviewing to Explore Meanings of Consumption”, In R. Harrison, T. Newholm and D. Shaw, 2005 (ed.). The Ethical Consumer. London: Sage Publications.

Clavin, B., and Lewis, A. (2005), "Focus Groups on Consumers' Ethical Beliefs", In R. Harrison, T. Newholm and D. Shaw, 2005 (ed.). The Ethical Consumer. London: Sage Publications. 
Collis, J., and Hussey, R. (2003), Business Research: A Practical Guide for Undergraduate and Postgraduate Students ( $2^{\text {nd }}$ Ed.). Basingstoke: Palgrave Macmillan.

Cowe, R., and Williams, S. (2000), Who are the Ethical Consumers? Manchester: CoOperative Bank / MORI.

Crane, A. (1999), "Are you ethical? Please tick yes $\square$ or no $\square$ : on researching ethics in business organizations", Journal of Business Ethics. Vol. 20 No. 3, pp. 237-248.

Creyer, E.H., and Ross, W.T. (1997), "The influence of firm behaviour on purchase intention: do consumers really care about business ethics?", Journal of Consumer Marketing, Vol. 14 No. 6, pp. 421-432.

Datamonitor, (2005a), "Being ethical or being cool: young adults can't make the choice", MarketWatch: Global Round-up. November, 34.

Diener, E., and Crandall, R. (1978), Ethics in Social and Behavioural Research. Chicago: The University of Chicago Press.

Donaldson, T., and Dunfee, T.W. (1994), “Toward a unified conception of business ethics: integrative social contracts theory", Academy of Management Review. Vol. 19 No. 2, pp. 252-284.

Edvardsson, B., Enquist, B., and Hay, M. (2006), "Values-based service brands: narratives from Ikea", Managing Service Quality. Vol. 16 No. 3, pp. 230-246.

Elliott, J. (2005), Using Narrative in Social Research: Qualitative and Quantitative Approaches. London: Sage Publications. 
Elliott, R. and Jankel-Elliott, N. (2003), "Using ethnography in strategic consumer research", Qualitative Market Research: An International Journal. Vol. 6 No. 4, pp. 215-223.

Experian (2003), Mosaic UK Group and Type Descriptions. Issue 2, December [online]. Available at: $<$ http://www.businessstrategies.co.uk/upload/downloads/mosaic/mosaic\%20uk\%20groups\%20and\%20type s.pdf>. [Accessed 28 October 2006].

Filmer, P., Jenks, C., Seale, C., and Walsh, D. (1998), "Developments in Social Theory", In: C. Seale (ed.), 1998. Researching Society and Culture. London: Sage Publications.

Firat, A.F., Dholakia, N. and Venkatesh, A. (1995), "Marketing in a postmodern world", European Journal of Marketing. Vol. 29 No. 1, pp. 40-56.

Foucault, M. (2002), The Archaeology of Knowledge. London: Routledge Classics.

Gilbert, N., ed. (2001), Researching Social Life ( $2^{\text {nd }}$ Ed.). London: Sage Publications.

Gold, R.L. (1958), Roles in Sociological Fieldwork. Social Forces. 36: 217-23.

Gummesson, E. (2007), "Access to reality: observations on observational methods", Qualitative Market Research: An International Journal. Vol. 10 No. 2, pp. 130-134.

Harrison, R. (2006), "Reflections on Reaching 100", Ethical Consumer. Vol. 100, pp. 2830.

Henn, M., Weinstein, M., and Foard, N. (2006), A Short Introduction to Social Research. London: Sage Publications.

Hinman, L.M. (2003). Ethics: A Pluralistic Approach to Moral Theory ( $3^{\text {rd }}$ ed.). Belmont: Wadsworth/Thomson Learning. 
Inteletex (2006), UK Wants Ethical Sourcing [online]. Available at:

$<$ http://www.inteletex.com/NewsDetail.asp?PubId=\&NewsId=4884>. [Accessed 2

December 2008.]

Irving, S., Harrison, R., and Rayner, M. (2005), "Ethical Consumerism - democracy through the Wallet", Journal of Research for Consumers [online]. Issue 3. Available at:

$<$ http://www.jrconsumers.com/academic_articles/issue_3/IrvingHarrisonRayner.pdf $>$ [Accessed 28 October 2007].

Joergens, C. (2006), "Ethical fashion: myth or future trend?", Journal of Fashion Marketing and Management. Vol. 10 No. 3, pp. 360-371.

Labour Behind the Label (2006), Who Pays for Cheap Clothes? Five questions the lowcost retailers must answer [online]. Available at:

$<$ http://www.labourbehindthelabel.org/images/pdf/low-cost-retailers-070706.pdf $>$. [Accessed 22 August 2007].

Lee, N., and Broderick, A. (2007), "The past, present and future of observational research in marketing", Qualitative Market Research: An International Journal. Vol. 10 No. 2, pp. 121-129.

Locke, K. (2001), Grounded Theory in Management Research. London: Sage Publications.

Lowrey, T.M., Otnes, C.C., and McGrath, M.A. (2005), "Shopping with consumers: reflections and innovations." Qualitative Market Research: An International Journal. Vol. 8 No. 2, pp. 176-188.

Mackie, J.L. (1977), Ethics: Inventing Right and Wrong. London: Penguin Books. 
Maital, S., Prakhaya, S., and Seshadri, DVR. (2008). "Bridging the chasm between management education, research and practice: moving towards the grounded theory approach. Vikalpa, 33 (1): 1-18.

Memery, J., Megicks, P., and Williams, J. (2005), "Ethical and social responsibility issues in grocery shopping: a preliminary typology", Qualitative Market Research: An International Journal. Vol. 8 No. 4, pp. 399-412.

Miles, M.B., and Huberman, A.M. (1994), Qualitative Data Analysis; An Expanded Sourcebook ( $2^{\text {nd }}$ ed. $)$. London: Sage Publications

Mintel, 2008. Retail Review - UK-March 2008. London: Mintel International group Ltd.

Mishler, E.G. (1991), Research Interviewing: Context and Narrative. Massachusetts: Harvard University Press.

Mowen, J.C. (1988), "Beyond consumer decision making", The Journal of Consumer Marketing. Vol. 5 No. 1, pp. 15-25.

Saunders, M., Lewis, P., and Thornhill, A. (2007), Research Methods for Business Students ( $4^{\text {th }}$ ed.). Harlow: Pearson Education.

Seale, C. (1998) "Qualitative Interviewing", In: C. Seale (ed.) (1998) Researching Society and Culture. London: Sage Publications.

Shaw, D., Hogg, G., Wilson, E., Shui, E., and Hassan, L. (2006), "Fashion victim: the impact of fair trade concerns on clothing choice", Journal of Strategic Marketing. Vol. 14 No. 4, pp. 427-440.

Silverman, D. (2001), Interpreting Qualitative Data: Methods for Analysing Talk, Text and Interaction ( $2^{\text {nd }}$ ed.). London: Sage Publications. 
Smith, N.C. (2001). Ethical Guidelines for Marketing Practice: A Reply to Gaski and Some Observations on the Role of Normative Marketing Ethics. Journal of Business Ethics. 32: 3-18.

Strauss, A., and Corbin, J.M. (1998), Basics of Qualitative Research: Techniques and Procedures for Grounded Theory ( $2^{\text {nd }}$ ed. $)$. California: Sage.

Tadajewski, M., and Wagner-Tsukamoto, S. (2006), “Anthropology and consumer research: qualitative insights into green consumer behaviour", Qualitative Market Research: An International Journal. Vol. 9 No. 1, pp. 8-25.

Valor, C. (2007), “The influence of information about labour abuses on consumer choice of clothes: a grounded theory approach", Journal of Marketing Management. Vol. 23 No. $7 / 8$, pp. 675-695.

Vitell, S.J., and Muncy, J. (1992), "Consumer ethics: an empirical investigation of factors influencing ethical judgments of the final consumer", Journal of Business Ethics. Vol. 11, pp. $585-597$.

Walsh, D. (1998), “Doing Ethnography”, In: C. Seale (ed.) (1998) Researching Society and Culture. London: Sage Publications.

Whysall, P. (2000), "Marketing Ethics - An Overview", The Marketing Review. Vol. 1 No. 2, pp. 175-195.

Wiggins, D. (2006), Ethics: Twelve Lectures on the Philosophy of Morality. London: Penguin. 